\title{
Detection of chlorides and moisture in concrete structures with ground penetrating radar
}

\author{
Johannes Hugenschmidt • Roman Loser
}

Received: 20 December 2006/Accepted: 13 June 2007/Published online: 4 July 2007

(C) RILEM 2007

\begin{abstract}
Corrosion of re-bar within reinforced concrete is a major problem in countries where salt is applied to roads for de-icing. Concrete structures are periodically inspected in order to monitor possible damage caused by chloride induced corrosion of the reinforcement. However, bridge decks covered with asphalt pavements are not accessible for visual inspection and probing is limited. As a result, the planning of rehabilitation of bridge decks is usually based on a small number of probes. Consequently, the condition of bridge decks can only be assessed with low certainty. Therefore, a method enabling to study the conditions of concrete bridge decks covered by asphalt pavements is desirable. This paper describes a laboratory experiment aiming at the investigation of the effects of moisture and chloride content on the amplitudes of radar signals. It can be shown that both, moisture and chloride content have a measurable influence on signal amplitudes. This may enable the
\end{abstract}

J. Hugenschmidt ( $\square)$

Road Engineering/Sealing Components Laboratory, Swiss Federal Laboratories for Materials Testing and Research, EMPA, Überlandstrasse 129, 8600 Dübendorf, Switzerland

e-mail: johannes.hugenschmidt@empa.ch

\section{R. Loser}

Laboratory for Concrete/Construction Chemistry, Swiss Federal Laboratories for Materials Testing and Research, EMPA, Überlandstrasse 129, 8600 Dübendorf,

Switzerland

e-mail: roman.loser@empa.ch future use of ground penetrating radar for the planning of probing campaigns or for the extrapolation of results obtained at single probing points.

Keywords Bridge decks - Chloride content . Ground penetrating radar · Corrosion · Nondestructive-testing

\section{Introduction}

Under normal conditions, the reinforcement in concrete is protected from corrosion mainly due to the high $\mathrm{pH}$-value of the pore solution. Under such conditions, a stable film forms on the steel surface which passivates the reinforcing steel and prevents the electrochemical processes taking place during corrosion [1]. However, this protective passivity layer can be destroyed due to carbonation of concrete or penetrating chlorides [2]. As soon as a certain threshold value of chlorides is exceeded, the protective passivity layer on the steel surface is locally destroyed and, in combination with water and oxygen, corrosion of the reinforcement can take place [3]. There are two consequences of chloride induced corrosion of steel. Firstly, the products of corrosion occupy a volume several times larger than the original steel which results in cracking and spalling of the concrete cover. Secondly, due to the highly localized chloride-induced corrosion at a small anode, pitting of the steel takes place which reduces 
the cross-sectional area of the steel decreasing its load-carrying capacity [2]. Corrosion of the reinforcement is the main cause of structural concrete deterioration and is therefore responsible for a large share of the cost for the rehabilitation of concrete structures [4].

Chloride induced corrosion of re-bar within reinforced concrete is not only a major problem in countries where structures are in contact with sea water but also in countries where salt is applied to roads for de-icing. Visual inspections of concrete structures carried out periodically are an established method to monitor their condition. Moreover, there are established methods based on the measurement of the potential of steel in concrete to detect active corrosion in reinforced concrete $[5,6]$. However, bridge decks covered by asphalt pavements are not accessible for visual inspection or potential measurements and in most cases probing is very restricted due to traffic. As a result, maintenance planning for bridges is usually based on experience and not on data of the real condition of such decks. A method for detecting zones of increased chloride content and/or moisture is therefore desirable to enable a better planning of repair work with respect to costs and scheduling.

Ground penetrating radar (GPR) has been suggested as a possible inspection method for condition assessment of bridge decks by several authors. Cardimona et al. [7] mapped the degradation of the radar signal (loss in amplitude and/or increase in travel time) as an indication of whether or not the region above the rebar is compromised in some fashion. Scheff and Chen [8] describe a comparison between GPR and chain drag results in a delamination survey on a concrete bridge deck and find that the results of the two methods do not fit very well. Roberts [9] compares results of GPR deterioration surveys on several New Hampshire bridge decks with ground truth and conventional (destructive) survey techniques and finds that results compare favorably. Shin and Grivas [10] evaluate the accuracy of condition assessments using GPR based on thresholds for the rebar reflection and dielectric constant and suggest multi-sensor fusion techniques to provide improved capabilities in assessing the condition of bridge decks. Barnes and Trottier [11] provide a description of nine bridge deck deterioration surveys where radar data were searched manually for excess signal attenuation and reflectivity from the asphalt concrete interface. Their comparison of the radar results with chain drag and half-cell potential results leads to the conclusion that GPR can present a viable option for estimating concrete deterioration repair quantities. Hugenschmidt [12] describes the application of a method based on the damping of the signal within the concrete of a bridge deck in Switzerland possibly caused by increased moisture and chloride content. However, a verification of the results obtained was not possible as the bridge is still in service. Finally, radar equipment manufacturers [13] are promoting their products as a tool for condition assessment of bridge decks and an ASTM Standard [14] describes the detection of delaminated areas on bridge decks based on variations of the deck bottom echo.

This paper describes a laboratory experiment investigating the effects of moisture and chlorides in concrete on radar amplitudes. The changes of the quotient of reflection amplitudes are evaluated as a possible approach for mapping problem zones on concrete bridge decks covered with asphalt pavements.

\subsection{Radar principles}

Ground penetrating radar is an electromagnetic investigation method. It is also known as GPR, surface penetrating radar or electromagnetic reflection method. Mostly it is used in reflection mode where a signal is emitted via an antenna into the structure under investigation. Reflected energy caused by changes in material properties is recorded (Fig. 1) and analyzed.

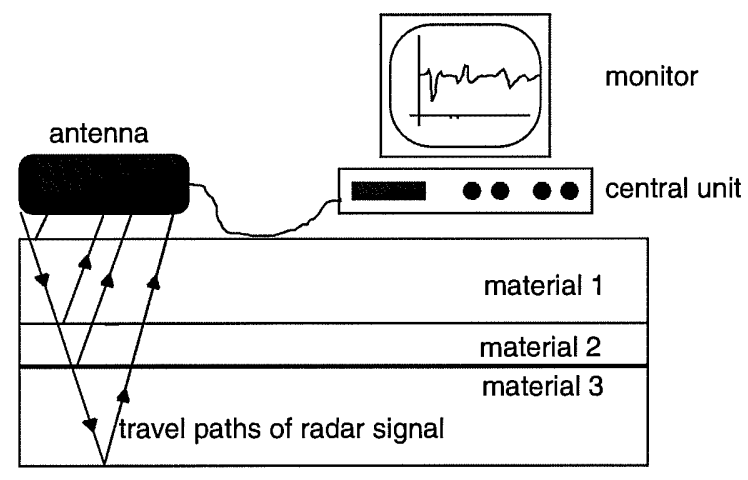

Fig. 1 Radar principles 
A sketch of the emitted and recorded signal is presented in Fig. 2. The signal recorded is usually referred to as a scan or a trace. The vertical axis is a time axis, its length in non-destructive-testing of concrete bridges is typically less than $30 \mathrm{~ns}$.

The reflection amplitude at the interface between two materials depends on several factors such as the difference in material properties (particularly the difference of the dielectric constants of the two materials), the amplitude of the emitted signal or the damping of the radar signal in the materials above the interface.

Daniels [15] gives a detailed description of the concepts of GPR and its application on various problems from different fields of work.

\section{Experimental program}

\subsection{Specimens}

To study the influence of moisture and chloride content on radar amplitudes, nine concrete slabs were produced, each with dimensions of $0.90 \mathrm{~m} \times 0.75 \mathrm{~m} \times 0.08 \mathrm{~m}$ (Fig. 3). Three concrete mixtures with maximum aggregate size of $32 \mathrm{~mm}$, constant volume of paste (cement + water $+\mathrm{NaCl}$ ) but differences in chloride content were used. The different chloride contents were $0.0,0.4$ and 1.0 mass- $\%$ chloride referred to cement content. The chloride was added as $\mathrm{NaCl}$ dissolved in the mixing water. A chloride content of $0.4 \%$ is the upper limit accepted under normal circumstances (temperature, ph-value, no prestressed structures, etc.) by Swiss experts. Workability of fresh concrete was determined with flow table test [16] and the pressure method was used

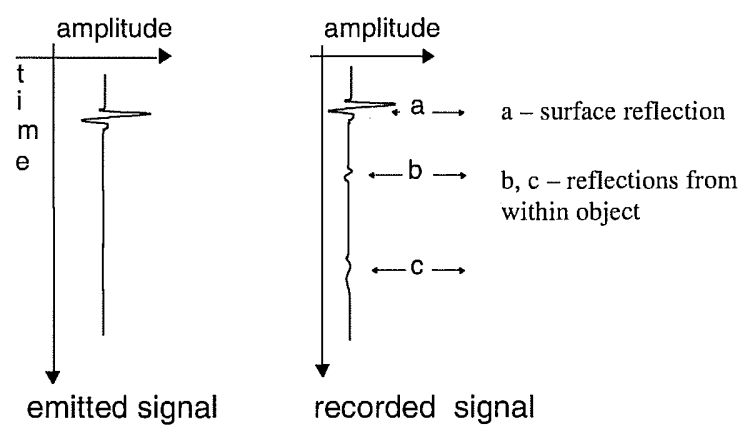

Fig. 2 Emitted and recorded signal

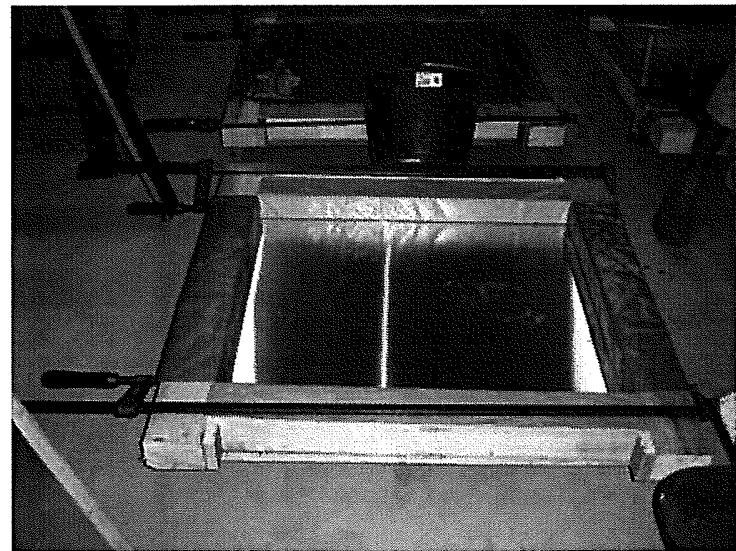

Fig. 3 Mould for the production of the specimens

for determining air content [17]. All mixtures had comparable fresh concrete properties. The concrete was cast in three moulds per mixture. An overview of the nine specimens is presented in Table 1.

The base of the mould was covered with an aluminum sheet simulating the reflecting reinforcement. After compaction, the specimens were stored at $20^{\circ} \mathrm{C}$ and $90 \%$ relative humidity (r.h.) for 2 days. Afterwards, the four sideboards of the mould were removed and one specimen of each mixture was moved to climates of 35\% r.h., $70 \%$ r.h. and $90 \%$ r.h. until the radar measurements were carried out. Additionally, two prisms $(360 \mathrm{~mm} \times 120 \mathrm{~mm}$ $\times 120 \mathrm{~mm}$ ) of each mixture were produced and stored at $20^{\circ} \mathrm{C}$ and $90 \%$ r.h.

There are differences between the slabs produced for the laboratory experiments and the situation on a real bridge. On bridges there is no aluminum sheet but a layer of rebar consisting of separate bars. The use of an aluminum sheet reduces the sensitivity of the experimental results to variations of the antenna position and orientation during radar data acquisition. As this is a desirable simplification of the experiment it was decided to use an aluminum sheet instead of single bars. On bridge decks, chlorides and moisture will rather penetrate into concrete during the life-span of the structure than being added during concrete production or absorbed during hydration. The experimental equivalent of the situation on bridge decks would be a mature specimen that is exposed to a chloride solution. However, this would introduce several factors such as concentration of chloride solution or duration of exposition that are difficult to 
Table 1 Storage, composition and workability of the different mixtures

\begin{tabular}{llllllllll}
\hline Mixture [-] & $\begin{array}{l}\text { Storage } \\
{[\% \text { r.h.] }}\end{array}$ & $\begin{array}{l}\text { Aggre-gate } \\
{\left[\mathrm{kg} / \mathrm{m}^{3}\right]}\end{array}$ & $\begin{array}{l}\text { CementCEM } \\
\mathrm{I} 42.5 \mathrm{~N}\left[\mathrm{~kg} / \mathrm{m}^{3}\right]\end{array}$ & $\begin{array}{l}\text { Water } \\
{\left[\mathrm{kg} / \mathrm{m}^{3}\right]}\end{array}$ & $\begin{array}{l}\text { Water/cementratio } \\
{[-]}\end{array}$ & $\begin{array}{l}\mathrm{NaCl} \\
{\left[\mathrm{kg} / \mathrm{m}^{3}\right]}\end{array}$ & $\begin{array}{l}\text { Vol. of } \\
\text { paste }\left[\mathrm{l} / \mathrm{m}^{3}\right]\end{array}$ & Flow [cm] & $\begin{array}{l}\text { Air } \\
\text { content } \\
{[\%]}\end{array}$ \\
\hline $0.0 \mathrm{Cl}, 35 \%$ & 35 & 1,937 & 310 & 155 & 0.50 & 0.00 & 254 & 43 & 1.0 \\
$0.0 \mathrm{Cl}, 70 \%$ & 70 & & & & & & & & \\
$0.0 \mathrm{Cl}, 90 \%$ & 90 & & & & & & & \\
$0.4 \mathrm{Cl}, 35 \%$ & 35 & 1,937 & 306 & 155 & 0.50 & 2.02 & 254 & 44 & 1.1 \\
$0.4 \mathrm{Cl}, 70 \%$ & 70 & & & & & & & & \\
$0.4 \mathrm{Cl}, 90 \%$ & 90 & & & & & & & \\
$1.0 \mathrm{Cl}, 35 \%$ & 35 & 1,937 & 301 & 155 & 0.51 & 4.96 & 254 & 44 & 1.0 \\
$1.0 \mathrm{Cl}, 70 \%$ & 70 & & & & & & & & \\
$1.0 \mathrm{Cl}, 90 \%$ & 90 & & & & & & & &
\end{tabular}

estimate. In addition, chloride profiles in several locations would be necessary to control the progress of water and chlorides within the concrete. It was therefore decided to simplify and accelerate the experiment by adding the chloride to the mixture and storing the specimens at different relative humidities. The results of the concrete testing suggest that this simplification is acceptable.

\subsection{Concrete testing}

At different concrete ages (up to 127 days), the change of weight of the nine slabs was determined by weighing. This change in weight is caused by the absorption (90\% r.h.) and loss of water (70\% and $35 \%$ r.h.) and therefore it is an indicator for change in moisture content of the concrete. In order to characterize the concrete of the three mixtures, compressive strength was measured on prisms at the age of 28 days according to EN-12390-3 [18]. Furthermore, one core sample ( $68 \mathrm{~mm}$ in diameter) was taken from each slab after 136 days in order to determine compressive strength.

\subsection{Radar data acquisition}

Radar data were acquired 99 days after the production of the specimens. The acquisition parameters are shown in Table 2.

The model 4205 antennas were chosen as they are part of Empas's mobile radar acquisition system for asphalt pavements and bridge decks shown in Fig. 4. As the signal of the model 4205 antennas is known to drift, the radar unit with the antennas connected was
Table 2 Data acquisition parameters

\begin{tabular}{ll}
\hline Radar unit & GSSI SIR-20 \\
Antennas & GSSI model 4205 horn \\
Antenna height above specimen & $0.25 \mathrm{~m}$ \\
Data processing during acquisition & None
\end{tabular}

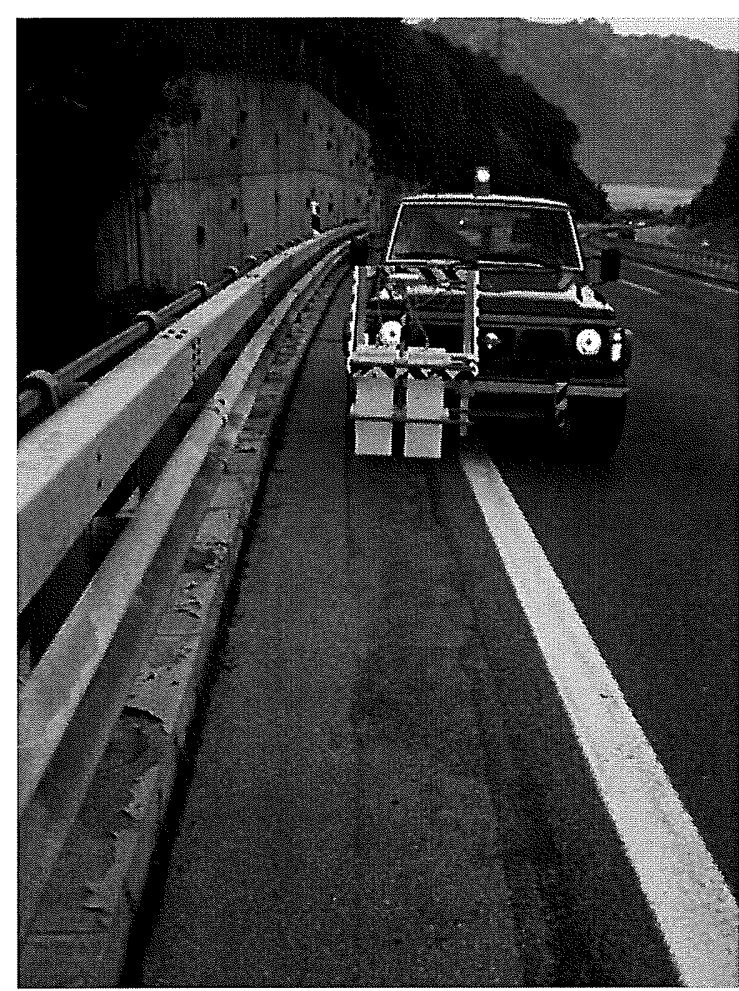

Fig. 4 Empa's mobile acquisition system 
switched on $1 \mathrm{~h}$ before the start of the actual data acquisition. In addition, data were acquired on a metal plate before and after the measurements on each specimen. The antennas were placed in the center of the specimens and in four locations close to the center to avoid edge effects. Data were acquired in continuous mode while the antennas were left stationary above the specimens. A photograph of the radar antennas placed above one of the specimens during data acquisition is shown in Fig. 5.

\section{Results and discussion}

\subsection{Concrete testing}

As it can be seen in Fig. 6, compressive strength of the concrete after storage of 28 days at $90 \%$ r.h. is decreasing with increasing chloride content. The maximum decrease is $10 \%$ (in relation to the maximum value).

The differences in w/c-ratio and cement content (Table 1) are too small to explain the variations in compressive strength. Since the main systematic difference of the three mixtures is chloride content (same mix design, same storage), chlorides in fresh concrete directly affect compressive strength in a negative manner.

The change in weight of the different slabs is shown in Fig. 7. While the slabs stored at 35\% r.h. and $70 \%$ r.h. loose weight, the slabs at $90 \%$ r.h. absorb moisture and gain weight. Moisture content in

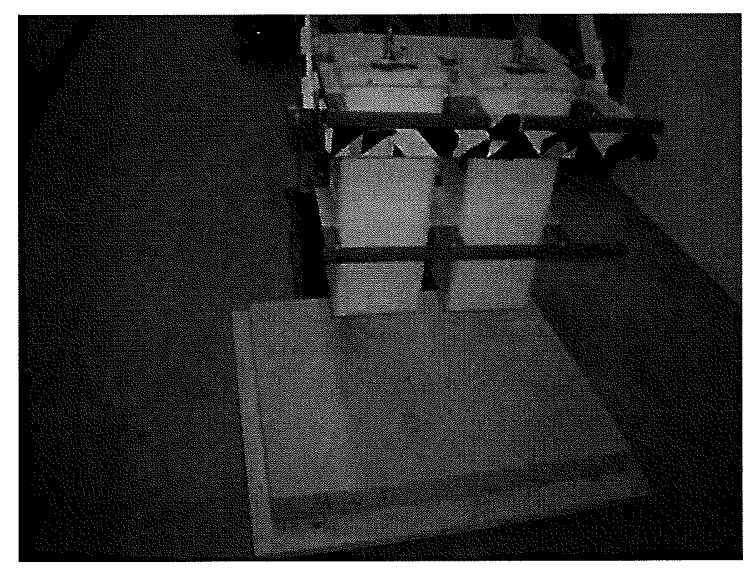

Fig. 5 Antennas positioned above specimen during data acquisition

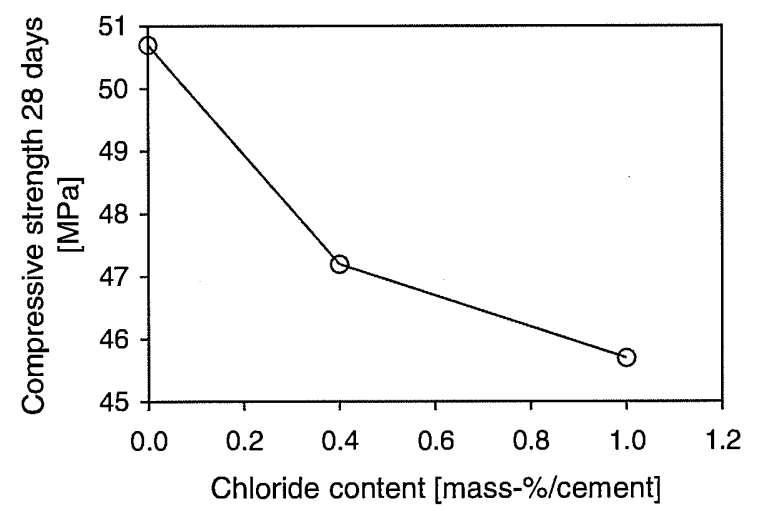

Fig. 6 Compressive strength after 28 days storage at $90 \%$ r.h. versus chloride content

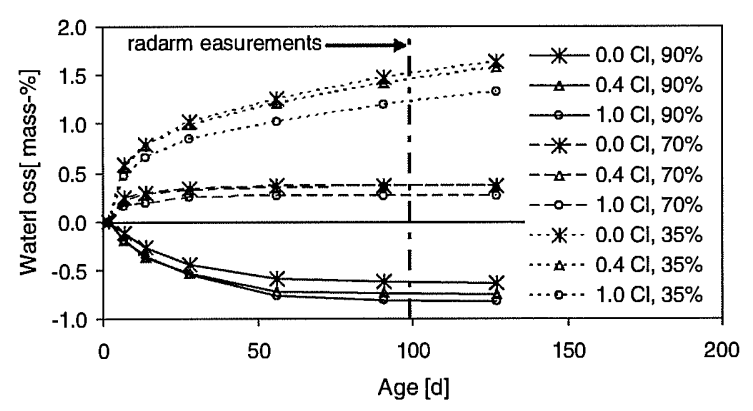

Fig. 7 Water loss (mass-\% of the total concrete weight) of the slabs stored at different relative humidities

concrete is additionally influenced by the addition of sodium chloride. Due to the hygroscopic properties of the salts formed, the moisture loss at constant r.h. is decreasing with increasing sodium chloride content. On the other hand, the absorption of moisture at $90 \%$ r.h. is increasing with increasing sodium chloride content.

However, the differences in weight caused by the changing r.h. are considerably higher than the differences caused by the hygroscopic salts. The equilibrium for $90 \%$ r.h. and $70 \%$ r.h. is already reached after 99 days and therefore, the on-site conditions for real structures are well represented.

Compressive strength of concrete after 136 days of curing is dependent on the r.h. of storage (Fig. 8). With increasing humidity, the compressive strength is increasing as well. Since only one core sample for each slab was tested, there is a certain variance in the results. Compressive strength after 136 days seems to 


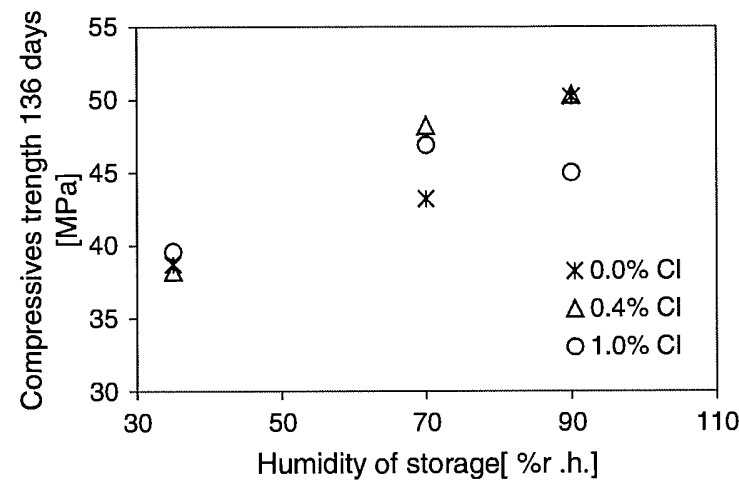

Fig. 8 Compressive strength after 136 days versus humidity of storage

be almost independent of chloride content. This is different from the results obtained after 28 days in $90 \%$ r.h.

\subsection{Radar amplitudes}

After the data acquisition, data were stacked 50 fold (50 neighboring traces were added together for noise suppression). No further processing steps were applied to the data. A plot of the signals obtained in the centers of four of the specimens is presented in Fig. 9. The reflections from the top of the concrete (marked with an arrow) with a two-way-traveltime (twt) in between 6 and $8 \mathrm{~ns}$ and the reflections from the aluminum sheet with a twt between 8 and $10 \mathrm{~ns}$ are clearly visible.

When comparing the data from the $0.0 \% \mathrm{Cl}-35 \%$ r.h. specimen (top left) with the $1.0 \% \mathrm{Cl}-90 \%$ r.h. specimen (bottom right) the reduced reflection amplitude at the aluminum sheet is obvious for $1.0 \% \mathrm{Cl}$ $90 \%$ r.h. concrete. In addition there seems to be a slight increase of the top of concrete reflection amplitude for the $1.0 \% \mathrm{Cl}-90 \%$ r.h. specimen. The $0.0 \% \mathrm{Cl}-90 \%$ r.h. and the $1.0 \% \mathrm{Cl}-35 \%$ r.h. specimens seem to have slightly reduced reflection amplitudes for the aluminum sheet when compared to the $0.0 \% \mathrm{Cl}-35 \%$ r.h. specimen.

In order to quantify the effects of moisture and chloride content on the signal amplitudes, mean values of the reflection amplitudes for the concrete surface and the aluminum sheet were computed for all specimens. For the concrete surface reflection the results for the nine specimens are summarized in Table 3.

A graphical chart of those results is presented in Fig. 10. Obviously the reflection amplitude at the concrete surface depends both on the humidity and the chloride addition with the humidity having a stronger influence. The difference between the minimum and maximum amplitudes is $18 \%$ of the maximum amplitude.

The results for the aluminum sheet reflection are summarized in Table 4. A graphical chart of the
Fig. 9 Signals from four specimens, top left $0.0 \% \mathrm{Cl}$ $35 \%$ r.h., top right $0.0 \% \mathrm{Cl}-$ $90 \%$ r.h., bottom left $1.0 \%$ $\mathrm{Cl}-35 \%$ r.h. and bottom right $1.0 \% \mathrm{Cl}-90 \%$ r.h.

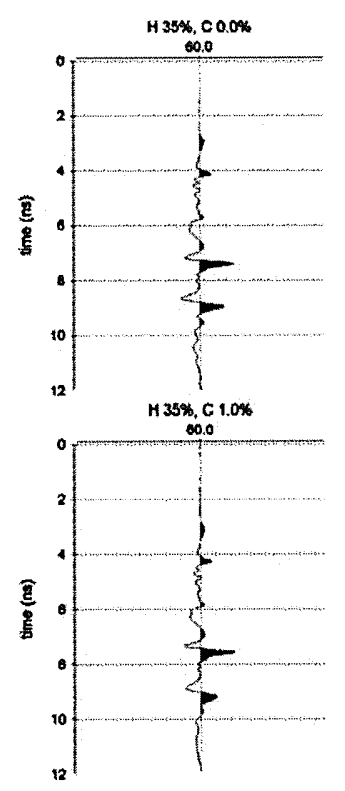


Table 3 Concrete surface reflection amplitudes

\begin{tabular}{llll}
\hline Chloride addition (\%) & \multicolumn{3}{l}{ Relative humidity } \\
\cline { 2 - 4 } & $35 \%$ & $70 \%$ & $90 \%$ \\
\hline 0.0 & 10,675 & 11,374 & 11,986 \\
0.4 & 10,832 & 11,638 & 12,204 \\
1.0 & 10,824 & 11,946 & 13,017 \\
\hline
\end{tabular}

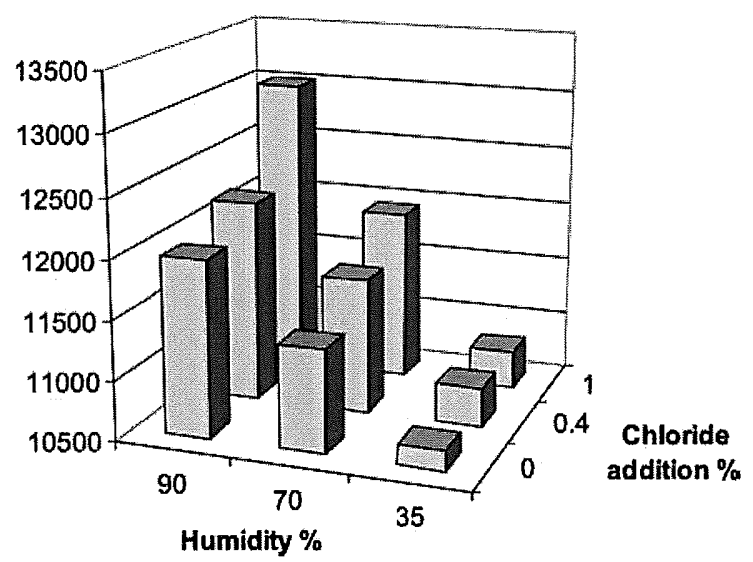

Fig. 10 Concrete surface reflection amplitudes

results is shown in Fig. 11. Please note that both the humidity and the chloride content axis were turned with respect to Fig. 10 to increase the readability of the chart. Obviously the reflection amplitude depends both on the humidity and the chloride content with both having a similar influence. The difference between the minimum and maximum amplitudes is $48 \%$ of the maximum amplitude and is thus considerably larger than for the concrete surface reflection.

When inspecting bridge decks, the energy emitted via the antenna is submitted to damping within the asphalt pavement. Absolute amplitudes are therefore of limited use for the investigation of chloride content and humidity. The quotient of the concrete surface

Table 4 Aluminum sheet reflection amplitudes

\begin{tabular}{llll}
\hline Chloride addition (\%) & \multicolumn{3}{l}{ Relative humidity } \\
\cline { 2 - 4 } & $35 \%$ & $70 \%$ & $90 \%$ \\
\hline 0.0 & 7,812 & 6,645 & 5,939 \\
0.4 & 6,549 & 5,523 & 5,137 \\
1.0 & 5,540 & 4,730 & 4,065 \\
\hline
\end{tabular}

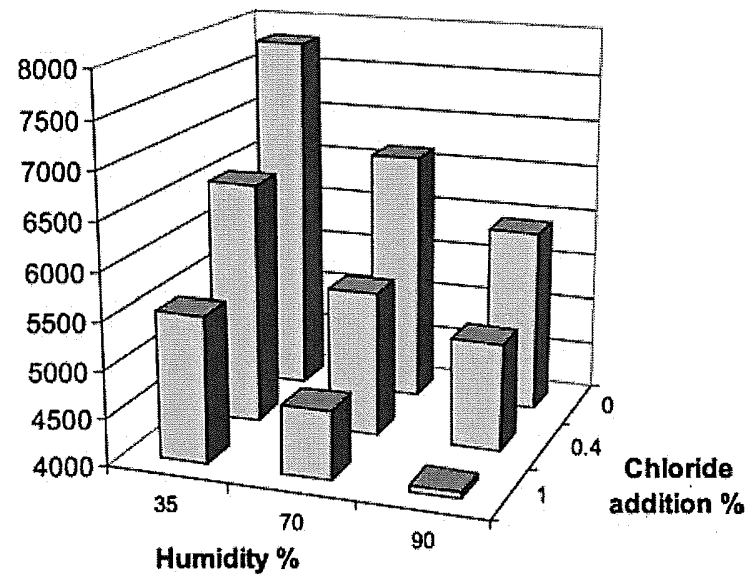

Fig. 11 Aluminum sheet reflection amplitudes

reflection and the rebar reflection amplitudes can be expected of being independent of the damping within the pavement. In addition, as those two amplitudes are related inversely to humidity and chloride content, an enhancement of the detectability can be expected.

In Table 5, the quotient of concrete surface and aluminum sheet reflection amplitudes as computed from the Tables 3 and 4 are presented and in Fig. 12 the corresponding graphical chart is shown. The difference between the minimum and maximum quotients is $57 \%$ of the maximum amplitude and thus larger than the differences for the concrete surface reflection or the aluminum sheet reflection alone, which should increase the stability of this approach on real bridges where numerous factors will affect the quality of results.

\section{Conclusions}

In a laboratory experiment it has been shown that both moisture and chlorides have a measurable

Table 5 Quotient of reflection amplitudes

\begin{tabular}{llll}
\hline Chloride addition (\%) & \multicolumn{3}{l}{ Relative humidity } \\
\cline { 2 - 4 } & $35 \%$ & $70 \%$ & $90 \%$ \\
\hline 0.0 & 1.37 & 1.71 & 2.02 \\
0.4 & 1.65 & 2.11 & 2.38 \\
1.0 & 1.95 & 2.53 & 3.20 \\
\hline
\end{tabular}




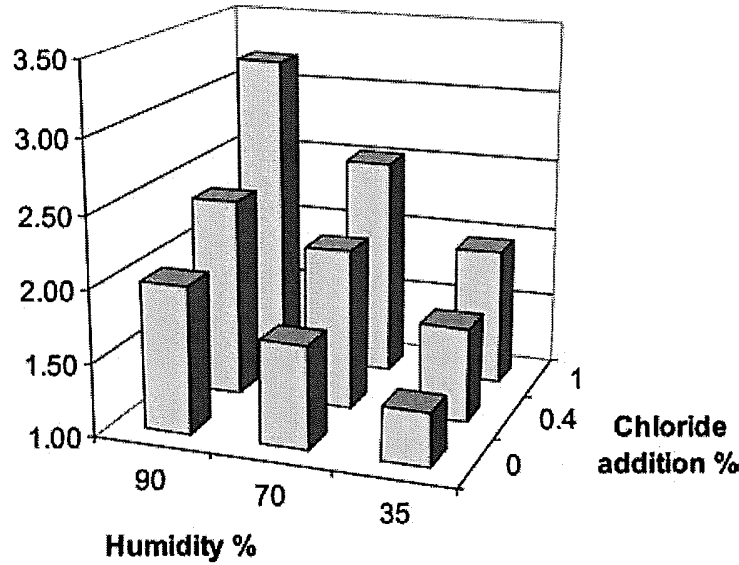

Fig. 12 Quotient of reflection amplitudes

influence on the reflection amplitudes of radar signals at the concrete surface and an aluminum sheet situated below the concrete specimen.

The simplified production of the specimens (adding of chloride during production and storage at different relative humidities during hydration) does change concrete properties. The main difference is clearly caused by storage at different r.h. This suggests that the micro-structure of the concrete is not influenced substantially by the addition of chlorides during production. Thus, the simplified production of the specimens seems to be acceptable with respect to the radar results.

The computation of the quotient between the reflection amplitudes at the concrete surface and the aluminum sheet provides in the laboratory experiment a reasonable approach for the detection of both chloride content and humidity in concrete. However, further investigations are needed to transfer these laboratory results to real structures.

Acknowledgements The work presented here is sponsored by the Building Department of Canton Vaud and the Swiss Federal Roads Authority (AGB2005/009).

\section{References}

1. Pourbaix M (1966) Atlas of electrochemical equilibria in aqueous solutions. Pergamon Press, Oxford
2. Neville AM (1995) Properties of concrete, 4th edn. Longman, Essex, pp 277-284, 497-506 and 563-566

3. Montemor MF, Simões AMP, Ferreira MGS (2003) Chloride-induced corrosion on reinforcing steel: from the fundamentals to the monitoring techniques. Cem Concr Compos 25:491-502

4. Guettala A, Abisi A (2006) Corrosion degradation and repair of concrete bridge. Mater Struct 39:471-478

5. Van Deveer JR (1975) Techniques for evaluating reinforced bridge decks. ACI J 12:697-704

6. Elsener B, Wojtas H, Böhni H (1993) Inspection and monitoring of reinforced concrete structures-electrochemical methods to detect corrosion. In: Proceedings of the 12th international corrosion Congress. Houston, 20-24 september 1993, pp 3260-3270

7. Cardimona S, Willeford B, Wenzlick J, Anderson N (2000) Investigation of bridge decks utilizing ground penetrating radar. International conference on the application of geophysical technologies to planning, design, construction and maintenance of transportation facilities. St. Louis/USA

8. Scheff J, Chen R (2000) Bridge deck inspection using chain drag and ground penetrating radar. In: Ansari $\mathrm{F}$ (ed) Condition monitoring of materials and structures. American Society of Civil Engineers

9. Roberts G (2002) Use of ground penetrating radar to delineate bridge deck repair areas. New Hampshire Department of Transportation, Report Nr. FHWA-NH-RD$12323 \mathrm{~S}$

10. Shin $\mathrm{H}$, Grivas $\mathrm{AD}$ (2003) How accurate is ground penetrating radar (GPR) for bridge deck condition assessment? 82nd annual meeting of the Transportation Research Board, January 12-16 2003, Washington DC/USA, CDROM

11. Barnes C, Trottier JF (2004) Effectiveness of ground penetrating radar in predicting deck repair quantities. J Infrastruct Syst 10(2):69-76

12. Hugenschmidt $\mathbf{J}$ (2005) Zuverlässigkeit und Genauigkeit von Georadar-Ergebnissen auf Betonbrücken. Federal Department of Environment, Transport, Energy and Communications, Swiss Federal Roads Authority, Report Nr. 582, March 2005 (in German)

13. Websites of GSSI (Geophysical Survey Systems Inc., Salem, NH, USA, www.gssi.com) and Sensors \& Software (Sensors \& Software Inc., Mississauga, Ont., Canada, www.sensoft.ca) accessed on December 6, 2006

14. ASTM Designation D 6087-03 (2005) Standard test method for evaluating asphalt-covered concrete bridge decks using ground penetrating radar. Annual Book of ASTM Standards, 04.03, Am Soc Test Mat, pp 698-701

15. Daniels D (2004) Ground penetrating radar, 2nd edn. The Institution of Electrical Engineers

16. EN 12350-5 (2001) Testing fresh concrete-Part 5: Flow table test

17. EN 12350-7 (2001) Testing fresh concrete-Part 7: Air content-pressure methods

18. EN 12390-3 (2002) Testing hardened concrete-Part 3: Compressive strength of test specimens 